\title{
AS CONQUISTAS NA LEGISLAÇÃO DO DIREITO DAS CRIANÇAS PEQUENAS À EDUCAÇÃO E OS DESAFIOS PARA SUA EFETIVAÇÃO
}

\author{
Claudia Pereira de Pádua Sabia ${ }^{1}$ \\ ${ }^{1}$ Docente do Mestrado em Educação da Universidade do Oeste Paulista, Doutora em Educação pela UNESP/Marília.
}

\begin{abstract}
RESUMO
Este artigo objetiva apresentar um breve resgate histórico da Educação Infantil no Brasil com seus desdobramentos mais recentes. Destaca as conquistas na legislação, aborda os desafios a serem superados para a expansão com qualidade, diante do financiamento limitado e a formação de professores requerida para esta etapa de ensino. Utiliza como metodologia a pesquisa bibliográfica. Finaliza apresentando que o direcionamento das políticas de educação infantil adotadas no país têm provocado novos processos de exclusão social.

Palavras-chave: Educação Infantil, Legislação, Financiamento e Formação de Professores.
\end{abstract}

\section{ACHIEVEMENTS IN DE LAW FOR CHILDREN'S RIGHT TO EDUCATION AND THE CHALLENGES FOR ITS EFFECTIVENESS}

\begin{abstract}
This article presents a brief historical review of early childhood Education in Brazil with their latest developments. It is noteworthy achievements in legislation. Adresses the challenges to be overcome for the expansion and quality. In the face of limited funding and teacher'formation required to this schooling level uses the methodology of the bibliographic research. We end by pointing out that children education policies adopted in Brazil have arose new process of social exclusion.

Keywords: children education; legislation; public policies; funding; teachers' formation
\end{abstract}




\section{INTRODUÇÃO}

As mudanças na Educação Brasileira em curso tiveram como eixo orientador as reformas neoliberais implementadas a partir da década de 1990.

Conforme Torres (2001, p. 79),

\begin{abstract}
A uniformização da política educativa em escala global está vinculada ao crescente peso dos organismos internacionais no projeto e na execução da política educativa nos países em desenvolvimento. Isso vale particularmente para o Banco Mundial, o sócio mais forte da Educação para Todos, que liderou o cenário educativo na década de 1990.
\end{abstract}

Segundo a autora, o pacote de reforma educativa recomendado aos países em desenvolvimento, principalmente para a reforma da educação primária inclui: empréstimos e assessoria técnica da banca internacional para o diagnóstico, delineamento e execução da reforma; primazia da análise econômica na definição de problemas e das prioridades; ênfase na educação básica (e transferência dos recursos do ensino superior); "foco na pobreza" e nas políticas de compensação ou de "discriminação positiva" para os grupos mais desfavorecidos ou em "risco"; reforma administrativa como prioridade, elemento central e articulador, papel secundário da reforma curricular e pedagógica; descentralização da gestão e da autonomia da instituição escolar; ênfase na avaliação do rendimento escolar e na implantação de sistemas nacionais de avaliação de resultados; ênfase na tecnologia educativa e, em particular, do livro didático; promoção da educação à distância e das modalidades e materiais auto-instrutivos; congelamento dos salários dos professores e promoção de incentivos vinculados ao desempenho; impulso à capacitação em serviço, incluindo esquemas descentralizados na oferta de tal capacitação; política de financiamento compartilhado e recuperação de custos (contribuição econômica dos pais e da comunidade para pagar as contas da educação escolar local); consultas e busca de acordos para a validação das políticas; e um pacote de medidas voltadas para a melhoria da qualidade educativa nas instituições escolares.

No Governo de Fernando Henrique Cardoso, teve início a Reforma do Estado, e foram aprovadas a Lei de Diretrizes e Bases da Educação Nacional - LDB no 9.394/96, e a Emenda 14/96 e suas regulamentações que se constituíram como a base da reforma educacional apontada por Torres (2001).

Oliveira (1999, p. 71), nos esclarece a direção da reforma do Estado [...]

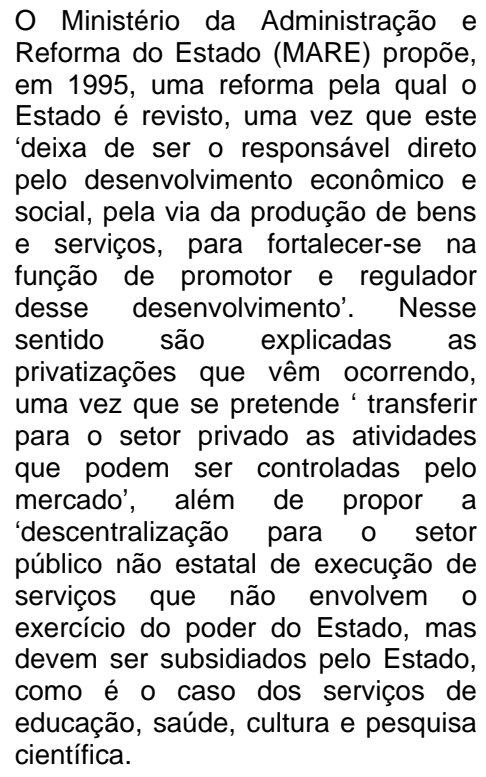

Portanto, a educação sofre os efeitos do novo Estado mínimo, e a mesma que é um direito de todos os cidadãos brasileiros, é aos poucos 'transformada em serviço' que deve ser pago pelo usuário. O processo de privatização da educação se viabiliza cada vez mais pela legislação e o Estado vem se desobrigando com a educação pública, gratuita e de qualidade; e a esfera federal repassando para as esferas estaduais e municipais sua operacionalização sem os correspondentes recursos necessários. É neste contexto de mudanças que se busca ampliar o acesso e melhorar a qualidade do atendimento da 
educação infantil, além do impacto da inclusão das crianças de seis anos no ensino fundamental.

Para desenvolver este trabalho, apresentamos uma breve história da Educação Infantil no Brasil. Na sequência, a legislação, destacando a Constituição Federal de 1988 - CF 1988, o Estatuto da Criança e do Adolescente ECA/ 1990, a Lei de Diretrizes e Bases da Educação Nacional - LDB/1996 e as Diretrizes Curriculares para a Educação Infantil. Finalizamos apontando a formação de professores para esta etapa de ensino, o financiamento e os desafios a serem superados neste nível de ensino.

\section{HISTÓRIA DA EDUCAÇÃO INFANTIL NO} BRASIL

Como em muitos países, o atendimento à infância no Brasil teve seu início marcado pela idéia de "assistência" ou "amparo" aos pobres e "necessitados", daí as creches, por exemplo, terem estado por tanto tempo vinculadas à associações filantrópicas ou aos órgãos de assistência e bem-estar social, e não aos órgãos educacionais nas diferentes esferas administrativas do país.

Segundo Corrêa (2007, p. 15),

\begin{abstract}
Um dos primeiros jardins da infância existentes no Brasil foi criado em 1896, como anexo à antiga Escola Normal do Estado, Caetano de Campos, na cidade de São Paulo. Com sua difusão, em 1940, por exemplo, Porto Alegre já contava com cerca de 40 jardins da infância".
\end{abstract}

Conforme a autora, os parques infantis surgiram na cidade de São Paulo em 1935 por ocasião da Criação do Departamento de Cultura daquele município e sob a direção de Mário de Andrade, idealizador do projeto. Na década de 1940, os parques infantis também se difundiram pelo país, ainda que de modo incipiente.
A partir de 1970 a oferta de educação infantil começou a se expandir de modo mais acentuado. Nos anos de 1970, o despertar dos movimentos sociais trouxe o tema para a agenda de suas reivindicações. Nos anos 80, pressões em diferentes sentidos provocaram, de um lado, a expansão da Educação infantil - El, segundo, de modo geral, um modelo 'a baixo custo' e, de outro, a consciência social da El como um direito das crianças pequenas à educação e um direito de assistência aos filhos de pais e mães trabalhadores.

De acordo com Rosemberg (2002, p. 35),

O período da expansão durante o
governo militar, ocorreu com custos
reduzidos, educadores leigos,
espaços improvisados, materiais
pedagógicos improvisados ou sua
escassez, como brinquedos, livros,
papéis, tintas.

A autora considera que nos países subdesenvolvidos a Educação Infantil tornou-se a rainha da sucata. Esses fatores resultaram em ambientes educacionais pouco favoráveis ao enriquecimento das experiências infantis.

Esse tem sido o modelo de política para a infância desde o início de sua expansão que foi mais penalizado ainda, a partir da década de 1990, sob as recomendações do Banco Mundial. Após a LDB/1996, sem financiamento específico passou à responsabilidade do Município que com a implantação do FUNDEF (Fundo de Manutenção e Desenvolvimento do Ensino Fundamental) em 1997, teve que priorizar o Ensino Fundamental em detrimento da Educação Infantil.

Cabe destacar a visão de uma série de autoras a esse respeito, como por exemplo, a de Rosseti; Ferreira et al. (2002, p. 76). Estas criticam "as políticas para a infância para os países em desenvolvimento, preconizadas pelo Banco Mundial, de atender pobremente a pobreza quando o alvo é a população pobre, negra e da zona rural". A autora se refere particularmente ao 
que está sendo proposto na forma de "programas alternativos" como "mãe-crecheira" ou "creches domiciliares".

Penn é outra autora que critica também as propostas do Banco Mundial para a Educação Infantil (2002, p. 12):

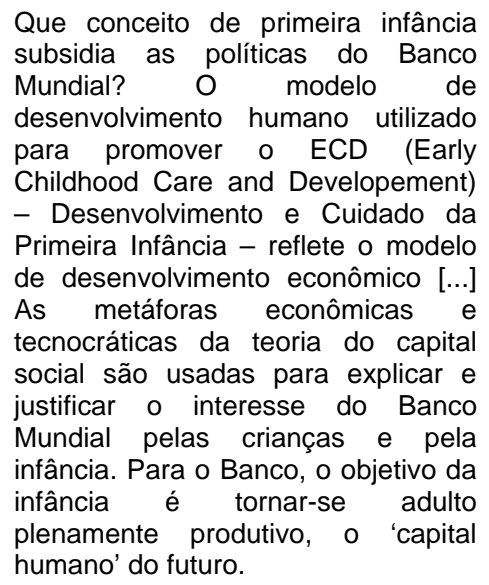

A autora tece sérias críticas em se utilizar os Estados Unidos como referência de Educação Infantil, já que o mesmo dispõe de um dos mais desiguais e injustos sistemas de educação infantil e que o mesmo se recusou a assinar a declaração da Organização das Nações Unidas ONU sobre os direitos da criança (o único país do mundo além da Somália). A sociedade americana considera normais as disparidades intensas entre ricos e pobres e interpreta tais desigualdades como sendo decorrentes de conquistas ou fracassos pessoais.

Análise da proposta do Plano Nacional de Educação do MEC (Ministério de Educação e Cultura) é feita por Rosemberg (2002, p. 54), destacando que o mesmo

[...] deu um forte passo atrás em relação tanto à Política Nacional de Educação Infantil (Brasil, 1993), quanto à LDB, pois:[...] defendeu a manutenção de crianças de até três anos em ambiente familiar, prevendo "programas alternativos" destinados a criar condições para essa permanência.

Portanto, os programas de ECD (Early Childhood Care and Developement) -
Desenvolvimento e Cuidado da Primeira Infância, financiados pelo Banco Mundial, planejados para redimir a pobreza, promovem modelos de Educação Infantil muito inferiores aos aceitáveis para as pessoas mais prósperas. Pouco fazem para ajudar os pobres, especialmente na medida em que endossam a exploração de mulheres, profissionais da Educação Infantil, em serviços de baixa remuneração. $O$ Brasil abre perspectivas para programas ECD, do tipo educação de mães, implantados no México, com empréstimos do Banco Mundial, a partir do nosso Plano Nacional de Educação.

\section{A LEGISLAÇÃO}

No Brasil, em termos de legislação regulamentando os direitos da criança à educação, tivemos conquistas consideráveis, ou seja, a Constituição Federal de 1988, o Estatuto da Criança e do Adolescente - ECA, de1990, a Lei de Diretrizes e Bases - LDB 9394 de 1996, em que o país adere formalmente à concepção da criança como sujeito de direitos, detentor de potencialidades a serem desenvolvidas, em sintonia com as normativas internacionais: Declaração Universal dos Direitos da Criança (UNICEF, 1959) e Convenção sobre os Direitos da Criança (ONU, UNICEF, 1989).

Destacaremos alguns artigos da Constituição de 1988, relacionados aos direitos da criança. O artigo 205 estabelece que a "educação é direito de todos". No artigo 208, inciso IV estabelece que "o dever do Estado com a Educação será efetivado mediante a garantia de: atendimento em creches e pré-escolas ás crianças de 0-6 anos de idade (opção da família). O artigo 227 coloca a criança e o adolescente como prioridade nacional. No artigo $7^{\circ}$, o inciso $X X V$, indica a educação infantil enquanto direito constitucional dos trabalhadores urbanos e rurais, a assistência gratuita aos filhos e dependentes 
desde o nascimento até os seis anos de idade em creches e pré-escolas."

Conforme Leite Filho (2001, p. 23), "o ECA, ao regulamentar o art. 227 da CF 1988, insere as crianças no mundo dos direitos, mais especificamente no mundo dos Direitos Humanos, reconhecendo-as como pessoas em condições peculiares de desenvolvimento, não as considerando como adultos e garantindo-lhes seus direitos". Para o ECA, a criança é considerada como sujeito de direitos. Direito de afeto, de brincar, de querer, de não querer, de conhecer, de sonhar e de opinar.

Na LDB, três artigos tratam da Educação Infantil, de forma sucinta e genérica. Reafirma-se que a educação de crianças com menos de 6 anos é a primeira etapa da educação básica. Consideramos importante destacar o artigo 31 que estabelece "na educação infantil a avaliação far-se-á mediante acompanhamento e registro do desenvolvimento sem o objetivo de promoção, mesmo para o acesso ao ensino fundamental". (SAVIANI, 1997, p. 211).

Foi destacado este artigo, pois Rosemberg (2002), ao analisar a implantação do modelo de Educação Infantil a baixo investimento público pelo Brasil, considera que o mesmo acarretou impactos nefastos como por exemplo, a retenção de crianças de 7 anos ou mais na préescola, crianças que deveriam estar no Ensino Fundamental, dentre outros citados.

Em 2005, foi aprovada a Lei Federal $n^{\circ}$ 11.114 que altera os artigos da LDB, com o objetivo de tornar obrigatório, a todas as crianças de 6 anos de idade, o início no Ensino Fundamental. Deste modo, a Educação Infantil atenderia as crianças de 0-5anos.

Segundo Arelaro (2005, p. 1047), "o autor parece ter pretendido transferir, simplesmente, o último ano da Educação Infantil, como se isso fosse uma passagem tranquila $e$ as duas instâncias educacionais fossem semelhantes". A autora considera que essa proposta só pretendeu ampliar a possibilidade de uso de recursos do FUNDEF com crianças pequenas, uma vez que os municípios estão com problemas para ampliar sua rede de Educação Infantil.

Faria (2005, p. 1029), em seus estudos propondo uma pedagogia da diferença na Educação Infantil, destaca justamente o aspecto que envolve essa antecipação: "romper como uma educação infantil antecipatória e preparatória para a escola obrigatória não é fácil, apesar de permanentes tentativas".

Nas Diretrizes Pedagógicas, o documento se refere as duas funções complementares e indissociáveis: cuidar e educar. A criança é concebida como um ser humano completo. A mesma traz em seu bojo a idéia de respeito à individualidade e ao ritmo próprio.

\section{FORMAÇÃO DE PROFESSORES}

A LDB/1996, em seu artigo 62, estabelece que

[...] a formação de docentes para atuar na educação básica far-se-à em nível superior, em cursos de licenciatura plena, em universidades e institutos superiores de educação, admitida como formação mínima para o exercício do magistério na educação infantil e nas quatro primeiras séries do ensino fundamental, a oferecida em nível médio, na modalidade normal.

Com a aprovação da nova Lei de Diretrizes e Bases da Educação Nacional - LDB/ 1996, posteriormente foi regulamentada a criação dos Institutos Superiores de Educação e o Curso Normal Superior como lócus preferencialmente de formação para a Educação Infantil e quatro primeiros anos do Ensino Fundamental, como alternativa à formação universitária nos cursos de Pedagogia.

Entretanto, o artigo 87 das Disposições Transitórias da LDB, "estabelecia que até o fim da década da educação somente seria admitidos professores habilitados em nível superior ou 
formados em treinamento em serviço". (SAVIANI, 1997, p. 224)

Esse prazo expiraria em 2007. Segundo Corrêa (2007), dada a ambivalência na redação do texto legal e diante de uma série de reclamações junto ao CNE Conselho Nacional de Educação), este órgão deliberou, em 2003, que valeria como certificação mínima para o exercício da docência em Educação Infantil e nas séries iniciais do Ensino Fundamental, a formação de nível médio, na modalidade Normal. (CORRÊA, 2007, p. 28)

Embora concordemos com o fato de que, dadas as disparidades regionais, a obrigatoriedade da formação superior fosse uma meta ambiciosa para um período de dez anos, entende-se que a supressão dessa exigência configura-se como um retrocesso, que tende a acomodação tanto dos profissionais quanto das instituições.

O fato da LDB/1996 ter diferenciado a Educação Infantil e primeiras séries do Ensino Fundamental dos demais, é considerado por Campos (1999), como perspectiva para a abordagem de formação dos professores que abre possibilidades muito interessantes. Destaca o autor que

\begin{abstract}
Talvez pela primeira vez em nosso país, começamos a pensar um perfil de educador adequado às características e necessidades de alunos em diferentes fases de seu desenvolvimento. Ou seja, começamos a pensar na criança, no adolescente, no jovem, no adulto que se encontra escondido atrás da palavra 'aluno. (CAMPOS, 1999, p. 127).
\end{abstract}

Esse posicionamento nos leva a refletir sobre as características dos cursos existentes, mesmo os de níveis superiores, que em sua grande maioria, não atendem às especificidades dos alunos, apontadas por Campos (1999).

A esse respeito, temos também a opinião de Machado (2000, p. 192), que considera

Um dos grandes desafios que se coloca aos projetos de formação é o

Colloquium Humanarum, Presidente Prudente, v. 6, n. 1, p. 25-33, jun. 2009. DOI: 10.5747/ch.2009.v06.n1.h062

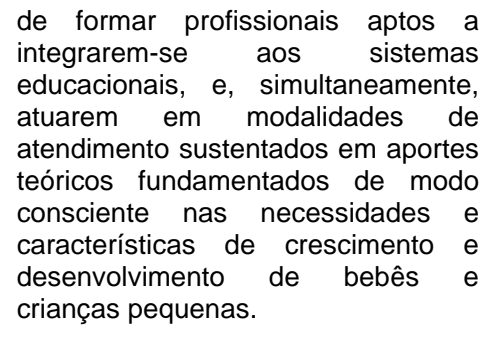

Atualmente, com a flexibilização da LDB, temos um conjunto de propostas híbridas de formação. Além das questões apresentadas sobre a formação inicial, que demandam ainda uma série de estudos e análise de propostas alternativas dada a sua complexidade, outras propostas vêm sendo viabilizadas como formação continuada pelo governo federal por meio da educação à distância e pelas secretarias estaduais de educação. No estado de São Paulo, - Programa mais Qualidade na Escola condicionará contratação de docentes habilitados à aprovação em treinamento. Foi criada a Escola de Formação de Professores de São Paulo, para docentes aprovados em concurso público, e que terão treinamento nesta escola com carga horária de 360 horas, durante quatro meses. Para os docentes que atuam na rede, será oferecido o curso de Pedagogia à distância, a partir de 2010, pela Universidade Estadual Paulista.

\section{FINANCIAMENTO}

A LDB 9394/96 não previa financiamento desta etapa de ensino. O FUNDEF que esteve em vigor até 2006 não contemplava a Educação Infantil, a qual ficou sob a responsabilidade dos municípios e estes tiveram de priorizar o Ensino Fundamental em detrimento da Educação Infantil e do Ensino Médio, quando este era oferecido.

No Fundo de Manutenção e Desenvolvimento da Educação Básica e de Valorização dos Profissionais da Educação FUNDEB, a Educação Infantil não estava prevista no projeto encaminhado ao Congresso.

Movimento Interfóruns da Educação Infantil do Brasil (MIEIB) fez várias manifestações 
conhecidas como "movimento dos fraldas pintadas", a favor da inclusão da mesma no fundo, conseguindo seu intento.

O FUNDEB, que entrou em vigor em 2007, prevê o financiamento para esta etapa, mas não define os percentuais, sujeitos a definição, anualmente, por Comissão Intergovernamental de Financiamento para a Educação Básica de Qualidade. Portanto, neste fundo toda a educação básica é contemplada. Os valores da complementação da União serão corrigidos anualmente pelo Índice Nacional de Preços ao Consumidor (INPC). Na Lei do Fundeb, existia também a previsão da fixação em lei do piso salarial profissional nacional para o magistério. Recentemente, foi aprovado o valor de $\mathrm{R} \$ 950,00$ como piso a partir do ano de 2010.

\section{DESAFIOS}

Na década de 1990, tivemos um pequeno percurso brasileiro na construção de uma Educação Infantil democrática. Após a votação da Constituição, uma nova equipe ocupou o setor no MEC/Coedi (Coordenação de Educação Infantil), tendo elaborado uma nova proposta nacional de política para esse nível de ensino.

De acordo com Rosemberg (2002, p. 41),

As diretrizes gerais dessa proposta,
resumidas no documento de política
de Educação Infantil, afastaram-se
do modelo "não formal" a baixo
investimento público, adotando
metas de expansão com
atendimento de qualidade (Brasil,
1993, p. 21). [...] Dentre as sete
diretrizes dessa proposta do MEC de
1993 , destaco as duas que mais
evidenciam a ruptura com o modelo
anterior: equivalência de creches e
pré-escolas, ambas tendo a função
de cuidar e educar crianças
pequenas como expressão do direito
à educação; formação equivalente
para o profissional de creche e pré-
escola em nível secundário e
superior.

Essas propostas foram elaboradas com a participação de segmentos, movimentos sociais, associações profissionais que já haviam experiências sobre este setor. Entretanto, a implantação foi interrompida com o governo Fernando Henrique Cardoso em 1994.

Este governo, ao adotar as orientações do Banco Mundial que priorizavam os investimentos públicos no Ensino Fundamental, retoma as propostas de programas "não formais" a baixo investimento público de Educação Infantil para crianças pobres.

Neste contexto político apresentado, os desafios são viabilizar o acesso e a qualidade do atendimento. É indispensável para essa tarefa, a qualificação dos professores, com formação inicial em nível superior e a formação continuada. Para isso necessitamos de investimento de porte, pois não se trata apenas de custeio, mas de expansão. E de expansão com qualidade. O atual sistema instalado carece de reformas, melhorias, já que foi concebido na perspectiva de atender precariamente. Segundo Rosemberg (2002, p. 39),especialmente no plano físico dos estabelecimentos, considerando a persistência de indicadores de baixa qualidade, como falta de infra-estrutura, de água, esgoto, bem como material pedagógico adequado às crianças pequenas (Censo da Educação Infantil 2000/2001).

Segundo Faria (2005, p. 1024), que utiliza dados do IPEA (2003-2004), "10,6\% das crianças de 0-3 anos freqüentam as creches e 65,6\% das crianças de 4-6 anos freqüentam as pré-escolas e ainda há muita fila de espera."

\section{CONSIDERAÇÕES FINAIS}

Embora o FUNDEB tenha significado alguns avanços, inclusive pela mobilização da comunidade acadêmica, precisamos de mais investimento em educação para ampliar o atendimento do sistema, aumentar significativamente os salários dos professores, disponibilizar equipamentos, materiais e 
instalações em número suficiente e funcionando adequadamente.

Os programas informais que empregam mães, supervisores, moradias particulares são bem mais baratas que programas oficiais. Essas propostas devem assumir muito mais um caráter de complementaridade, em relação às ações educativas, do que alternativas ou substitutas a elas.

Os autores citados neste texto indicam todo o tempo, o lado perverso das políticas de Educação Infantil adotadas no país para a expansão desde a década de 1970. Elas têm provocado novos processos de exclusão social. Nesse sentido, a expansão da Educação Infantil não significa obrigatoriamente um processo de democratização da educação, mas pode significar uma realocação, no sistema educacional, de segmentos sociais excluídos. No caso brasileiro, a inclusão acarreta, paradoxalmente, a exclusão.

Portanto, a expansão a baixo investimento e a persistência de modelos institucionais diversificados - creches públicas e creches conveniadas, pré-escolas públicas e conveniadas, classes de alfabetização geralmente abrem possibilidades ao oferecimento simultâneo de serviços com qualidade extremamente desigual.

Essa desigualdade no custeio/qualidade que penaliza crianças pobres e negras de diferentes formas tem sido denominado por Rosemberg (1999, p. 16) de "morte educacional anunciada".

Os educadores precisam continuar a luta por meio dos seus movimentos, reivindicando mais verbas para a Educação Infantil, a diminuição de professores leigos, a valorização dos profissionais, remunerações condignas e condições de trabalho satisfatórias, em benefício dos direitos das crianças pequenas a uma pedagogia da diferença, para a superação das desigualdades. Portanto, que o direito à educação tenha como pressuposto um ensino básico de qualidade para todos e que não (re)produza mecanismos de diferenciação e de exclusão social.

\section{REFERÊNCIA BIBLIOGRÁFICA}

ARELARO, L. R. G. O Ensino Fundamental no Brasil: Avanços, Perplexidades e Tendências. Educação \& Sociedade, Campinas: CEDES, v. 26, n. 92, p. 1039-1066, Especial, Out/2005.

CAMPOS, M. M. A formação de professores de 0-10 anos. In: BICUDO, M. A. V., SILVA JR., C. A. Formação do educador e avaliação educacional: formação inicial e contínua. v. 2. São Paulo: UNESP, 1999. (Seminários e Debates).

CORRÊA, B. C. A Educação Infantil. In: OLIVEIRA, R.P. (org.). Organização do Ensino no Brasil - Níveis e modalidades na Constituição Federal e na LDB. $2^{\text {a }}$ Ed. São Paulo: Xamã, 2007, p. 13-32.

FARIA, A. L. G. Políticas de Regulação, Pesquisa e Pedagogia na Educação Infantil, Primeira Etapa da Educação Básica. Educação \& Sociedade, Campinas: CEDES, v. 26, n. 92, p. 1013-1038, Especial, Out. 2005.

LEITE FILHO, A. Proposições para uma educação cidadã. In: GARCIA, R.L. e LEITE FILHO, A. (Orgs.). Em defesa da educação infantil. Rio de Janeiro: DP\&A, 2001, p. 29-58.

MACHADO, M. L .A. Desafios Iminentes para Projetos de Formação de Profissionais para Educação infantil. Cadernos de Pesquisa. São Paulo, n. 110, p. 191-202, jul/2000.

OLIVEIRA, C. A municipalização do ensino no

Brasil. Belo Horizonte: Autêntica, 1999. 
PENN, H. Primeira Infância: a visão do Banco Mundial. Cadernos de Pesquisa, São Paulo, n. 115, p. 7-24, mar. 2002.

ROSEMBERG, F. Expansão da Educação Infantil e Processos de Exclusão. Cadernos de Pesquisa, São Paulo, n. 107, p. 7-40, jul. 1999.

ROSEMBERG, F. Organizações Multilaterais, Estado e Políticas de Educação Infantil. Cadernos de Pesquisa, São Paulo, n. 115, p. 25-63, mar. 2002.

ROSSETTI-FREREIRA, M. C. et al. Políticas de Atendimento à Criança Pequena em Países em Desenvolvimento. Cadernos de Pesquisa, São Paulo, n. 115, p. 65-100, mar. 2002.

SAVIANI, D. A nova Lei da educação: trajetória, limites e perspectivas. Campinas: Autores Associados, 1997.

SENA, P. A Legislação do FUNDEB. Cadernos de Pesquisa (FCC), Campinas, Autores Associados, v. 38, n. 134, p. 319-340, maio / ago. 2008.

TORRES, R. M. Educação para Todos - A tarefa por fazer. Porto Alegre: Artmed, 2001. 